\title{
Service Learning and International Internships in Journalism Courses: A Pedagogy of Transformative Citizenship
}

\author{
By Twange Kasoma*
}

This study explores the concept of transformative citizenship using student data collected over a 3-year timeframe. Students enrolled in two reporting and writing courses and an international journalism course were post-evaluated. The reporting and writing courses incorporated service learning projects while the international journalism course culminated in short-term media internships in Zambia. Postevaluations of these courses showed that students highly valued the transformative sense of citizenship that resulted from their experiences. The study further found gender differences in this transformative sense of citizenship, particularly where international internships were concerned. Although the class sizes of the Journalistic Practice in Zambia course were small and had more male than female students, the former scored higher than their female counterparts on transformative citizenship indicators. The difference was explained away by prior travel experiences both within and outside the United States by the male students. For the female students, the Zambia trip was their first outside their native Virginia.

Keywords: internship, journalism, pedagogy, service-learning, transformative citizenship, Zambia

\section{Introduction}

Current shifts in journalism pedagogy are prioritizing the re-examination of the concept of citizenship. While this interrogation of citizenship is mostly being done from a micro or local/national perspective some scholars have called for its examination at the macro or global level (Deuze, 2001; Freedman, 2010; Holm, 2002). In Re-birth of a nation? Challenging "global citizens", Ron Israel (2013) defines a global citizen as someone who identifies with being part of an emerging world community and whose actions contribute to building this community's values and practices. By contrast, a local citizen identifies with and contributes to the growth of a specific nation. The demands and changes in the journalism profession in the $21^{\text {st }}$ century have also meant adopting teaching methodologies that not only transcend the local and/or global, but also seek to harmonize the two. Pedagogies that are growing in popularity that are meant to address this include service-learning and international internships. As forms of experiential learning, both have been deemed to motivate students into being active citizens in a democratic community. Pedagogically, the efficacy of service learning and international internships is rooted in John Dewey's educational and social philosophy.

\footnotetext{
* Assistant Professor, Radford University, USA.
} 
Dewey (1938) saw experience as a significant teacher. A type of teacher that provides students with a platform for reflection and critical thinking about how knowledge and skills learned in class can be applied to real life situations, including addressing problems in the world.

\section{Statement of the Problem}

Although experiential learning has been around for a while there is still a void in scholarship, especially where examining the benefits of integrating service-learning and international internships in journalism courses is concerned. Silverman (2008) citing a survey of members of the Association for Education in Journalism and Mass Communication noted that the most common communication courses that integrate service learning are public relations and media production/design courses. Journalism courses did not feature highly. Even more dire is integrating international internships in journalism courses. Steeves (2006) reiterated that international internships through study abroad contribute to efforts to diversify and internationalize the undergraduate curriculum. The over-arching question that guided this study therefore was:

How transformative do students find the integration of service learning and international internships in journalism courses to their sense of citizenship?

\section{Significance of Study}

This study contributes to filling the gap in literature noted above. Moreover, epistemologically, by aggregating service learning and international internships it helps provide a more holistic approach to students' perceptions of experiential learning. Past studies have tended to address the two experiential learning pedagogies singularly. Additionally, using both quantitative and qualitative techniques further enriches the study. Last, and perhaps most important, is the fact that the data for the study were collected over a three-year period and involved a total of five classes i.e. Writing, Reporting \& Editing I, two sections of Writing, Reporting \& Editing II and two sections of Journalistic Practice in Zambia. For courses with two sections, the data were collected over two different years. The advantage of a prolonged data collection timeframe is that the results show a pattern and rules out the possibility of the findings being a matter of chance.

\section{Literature Review and Theoretical Framework}

Theoretically experiential learning, under which the pedagogies of service learning and international internships fall, dates back to the 1890s. It draws its impetus from John Dewey's educational philosophy, which states that if 
education is to accomplish its ends for learners and for society, it must be based upon actual life experience. And that it is crucial that educators recognize and understand the connection between education and personal experience (Dewey, 1938). Today, educators acknowledge this connection amidst at varying levels. Some fields have done better than others. Focusing specifically on journalism, there is a dearth in scholarship examining the efficacy of the two pedagogies. Patwardhan, Sarow and Stuart (2013) are among scholars who endorse infusing various forms of experiential learning in the journalism and mass communication curriculum. They regard experiential learning as a transformative approach that helps students develop critical thinking and analytical abilities through viewing issues/events/topics through diverse cultural perspectives and viewpoints. Since scholars have tended to address the two experiential learning pedagogies of service learning and international internships singularly, this literature review will also proceed accordingly.

\section{Service Learning}

The National Service-learning Clearinghouse (2011) defines servicelearning as a teaching and learning strategy that integrates meaningful community service with instruction and reflection to enrich the learning experience, teach civic responsibility, and strengthen communities. Over the years, researchers have identified three main approaches to service-learning namely (a) critical citizenship and civic values (Morgan \& Streb, 2003; Sapp \& Crabtree, 2002); (b) social justice activism (Freire, 1970); (c) skill-set practice and reflexivity. According to Britt (2012), the three approaches converge on their attention to the development of students' identities, but they diverge on which particular facet of identity is nurtured and called forth - citizen, learner or social activist. In analyzing the latter, Pine (2008) attempted to situate and contextualize the social justice claims of service learning. While she found evidence of the social activist identity through service learning, she concluded that social context was crucial in order to make a meaningful connection to social justice aims. In addressing the facets of learner and citizen, Cohen and Kinsey (1994) studied 220 students in a mass communication and society course. They posed the question "Does the use of community service within the curriculum enhance an identifiable goal such as mastery of course material or increased understanding of citizenship in a democracy?". Their findings were affirmative for both facets and concluded that experiential learning was pedagogically superior to non-experiential learning. Andrew Furco, Director of Service-Learning \& Research Development Center at the University of California at Berkeley, states that as a form of experiential learning, internships share similarities with service learning. Furco places the two, plus practica, field education, and voluntary service on a continuum. At one end are internships and practica, which he labels as professional development. Their primary focus is on students' career development. At the other end are volunteer activities in which the emphasis is civic involvement and the services 
provided to recipients. Furco locates service learning in the middle of the continuum noting that it is unique in its "intention to equally benefit the provider and the recipient of the service as well as to ensure equal focus on both the service being provided and the learning that is occurring".

\section{Internships and International Internships}

Literature examining the value of journalism internships from students' perspectives is sporadic, particularly for international internships. Among scholars who have contributed to filling that void include Little (1981, as cited in Getz, 2002) who articulated nine distinct ways in which students can benefit from internships. These are an opportunity to (1) apply their knowledge of the field via first-hand participation; (2) learn new skills specific to their chosen profession; (3) acquire skills and attitudes necessary to function as adults; (4) develop the ability to learn from their mistakes; (5) develop an ethical perspective; (6) sample their career choices; (7) become responsible citizens; (8) gain access to knowledge that cannot easily be attained through classroom instruction; (9) identify problems for further study. Testing these, Getz (2002) in a study of journalism students' perceptions of the value of internships found that most viewed their internship experiences in positive light. From an international perspective, Steeves (2006) studied a journalism study abroad program to Ghana. She found that American students were eager to find out firsthand what it was like to live and practice journalism in another country and culture, particularly in the developing world. Despite some drawbacks, internships abroad were life-altering.

\section{Methods}

The sample for this study, which spanned a three-year timeframe, consisted of students enrolled in five journalism courses that integrated servicelearning or international internships. The students were drawn from the mass communications program at Emory \& Henry, a small liberal arts college in southwest Virginia. The two service learning courses were Reporting, Writing \& Editing I (MCOM 202), an introductory course and its advanced version Reporting, Writing \& Editing II (MCOM 302). During the first year of study, only MCOM 202 was earmarked for service learning. The class had an enrollment of 11 students. For the second and third year of study, only MCOM 302 had a service-learning component. The enrollments for the two sections were 10 and 12 respectively. The service-learning component for MCOM 202 involved mentoring students who worked on the Yearbook at a nearby high school. Specifically, the Emory \& Henry students (herein referred to as mentors) were paired up with mentees from Patrick Henry High School. The mentors met with their mentees fortnightly, provided advice on yearbook story ideas, the writing and reporting process, as well as layout and design ideas. The mentors and mentees also exchanged social media contact information and 
used that as another conduit for staying in touch without having to meet inperson.

As for MCOM 302, the service-learning component for the first year involved working with a local branch of Habitat for Humanity. The students were tasked with assisting with the organization's outreach program. Specific responsibilities included: Writing features on families that had benefitted from house-builds and putting together a video news release to highlight the organization's resale store. The second year's was working with the Virginia Creeper Trail Club (VCTC) on an oral histories project. VCTC is a private nonprofit whose purpose is to maintain, promote and preserve the Virginia Creeper Trail corridor. It helps develop and conduct public education programs regarding the Trail's scenic and natural qualities. Students were assigned a subject -- the majority of whom were senior citizens who have lived most if not all their life in that vicinity. Students met with and interviewed their subjects several times over the course of the semester to gather and preserve the rich oral history of the Trail.

In examining students' perceptions of how beneficial they found service learning, data were collected via a questionnaire, which contained 10 items cutting across the three facets referenced earlier (Britt, 2012). Of the 10, the two deemed appropriate indicators of transformative citizenship were (1) I was given sufficient freedom to shape the service-learning component of this course; and (2) The information I learned in this course is useful in my life. The questionnaire used a Likert scale to measure students' attitudes towards service learning and descriptive statistics were used to interpret the findings. In the subsequent MCOM 302 classes, which had service-learning components two additional transformative citizenship indicators were added to the questionnaire. These were (1) Have you seen any ripple effects, either in the project or in your own perspectives, as a result of this experience?; (2) What have you gained from your participation in the service-learning effort this semester?. These were qualitatively analyzed.

For international internships, two groups of students enrolled in MCOM 350 (Journalistic Practice in Zambia) participated. The timing for the first class coincided with the initial service-learning class. Four MCOM 350 students visited Zambia after concluding a spring class that introduced them to Zambian culture and equipped them with skills needed to practice journalism there. The students were required to intern at one broadcast and one print outlet. The media outlets the students interned at were (a) Muvi TV; (b) a privately-owned television station; (c) Zambia Daily Mail; (d) a state-owned newspaper; (e) Radio Phoenix a privately-owned radio station. The second class also of four coincided with yet another service-learning class. Taking into account student feedback from the seminal MCOM 350 course about feeling over-extended by having to intern at two different outlets, the second group was only required to intern for one. The dynamics worked out as follows (a) One male and one female student interned at the state-owned Times of Zambia and (b) two male students interned at Q-FM - a privately-owned radio station. To analyze data a qualitative method was used. Initially, first-person narratives 
in student reflection papers at the conclusion of their internships were scrutinized for interweaving themes. These themes were the basis for a phenomenological analysis, which involved identifying words in the reflection papers that conveyed strong emotion and alluded to behavioral/ transformational change. The words, which were deemed appropriate indicators of transformative citizenship, are bolded and italicized in the findings for emphasis. A 5-point continuum was employed to demarcate the results along gender lines.

\section{Findings}

The five classes yielded a total of 41 students. Course post-evaluations showed that they agreed that service learning and international internships enhanced their educational experience. The two pedagogies served as a handson platform for students to showcase/apply journalistic skills learned in class. Incorporating service learning and international internships in journalism courses provided students with a real-world laboratory to test their critical and problem-solving skills. Commencing with service learning, post-evaluations of the three courses with that component showed that the students appreciated how their sense of citizenship had been transformed. As shown in Figure 1, on the transformative citizenship indicator of being given sufficient freedom to shape the service-learning component, over half the class in all cases agreed. With $81.8 \%$ in a class of 11 agreeing, MCOM 202 students working on the Patrick Henry High School project had the highest percentage for this indicator. Students on the Virginia Creeper Trail and Habitat for Humanity service-learning projects scored $75 \%$ and $60 \%$ out of class sizes of 12 and 10 respectively.

Figure 1. Given Sufficient Freedom to Shape Service-Learning Component

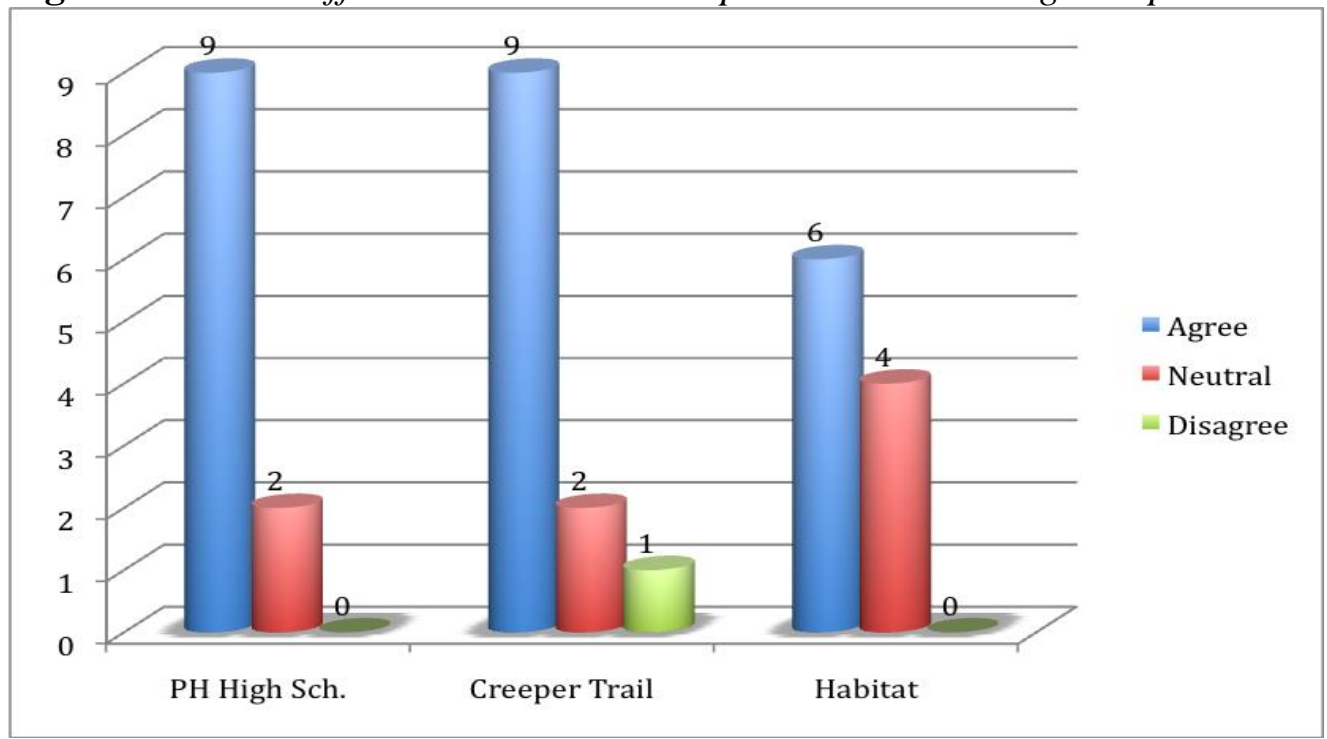

Source: Author's estimations. 
In contrast, for the second indicator "The information I learned in this course is useful in my life", $72.7 \%$ of the 11 MCOM 202 students agreed, while $100 \%$ of MCOM 302 students working on the Habitat for Humanity Project agreed. For the MCOM 302 Virginia Creeper Trail Project, 91.7\% agreed (Figure 2).

Figure 2. Information Learned in this Course is Useful in My Life

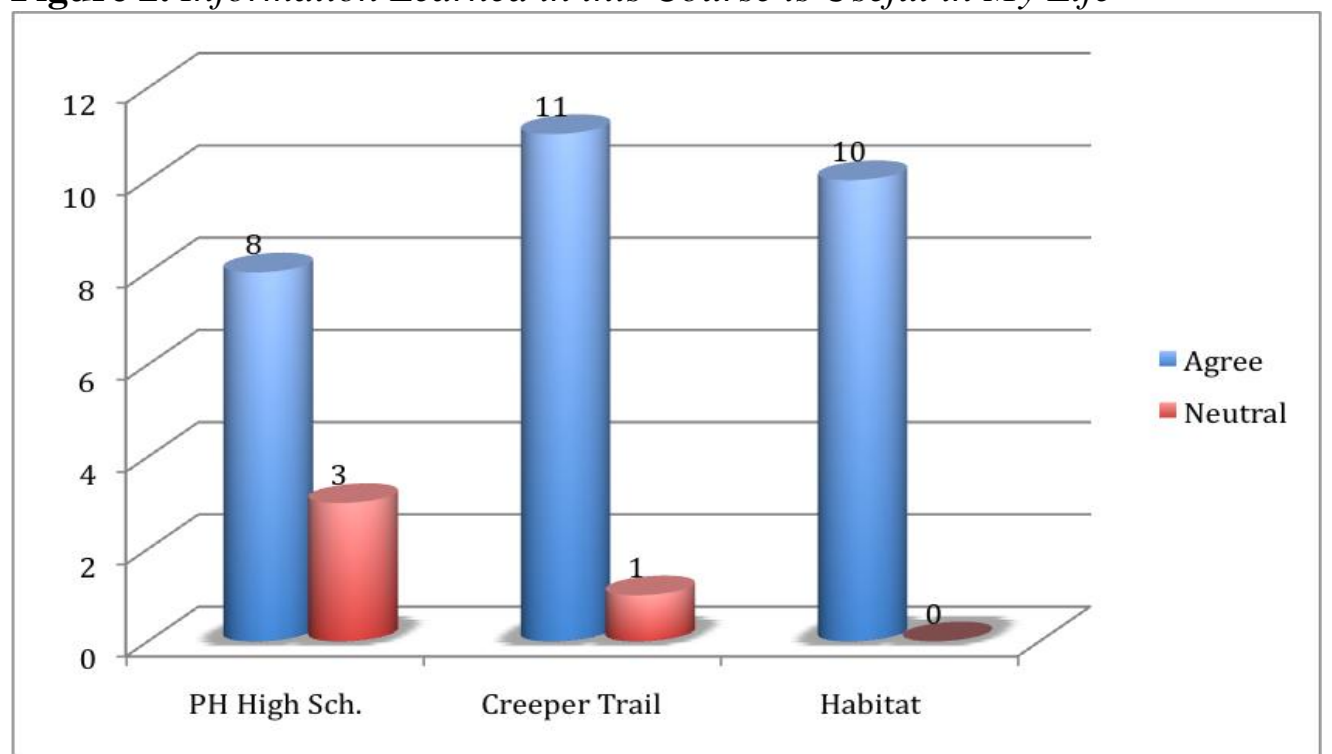

Source: Author's estimations.

For the two indicators that were exclusive to the Habitat for Humanity Project and Virginia Creeper Trail Project, namely "Have you seen any ripple effects, either in the project or in your own perspectives, as a result of this experience?" and "What have you gained from your participation in the service-learning effort this semester?" four frames emerged. The four frames, which are embodied in students' sentiments below were (1) Appreciation; (2) Empathy; (3) Volunteerism; (4) Respect.

- I want to volunteer my time more and get connected with the stories of Habitat.

- I have gained valuable experience and a newfound respect for what Habitat does.

- More understanding of how things work, more empathy.

- Opportunity to get out and be active in the community to help wonderful projects out like the Virginia Creeper Trail.

- I have gained an appreciation for the Virginia Creeper Trail and the surrounding community - I did not know what a resource it was until this project.

- A knowledge that there are people out there interested in preserving history even in a local small town - respect for them. 
As far as international internships go, Figure 3 illustrates the gender difference on a 5-point continuum. Male students scored higher than their female counterparts. However, some stated that this was not their first exposure to a foreign culture.

A typical male student summation of the experience was "...the study abroad trip to Zambia excelled (sic) anything I ever expected to gain out of my time in college. Not only did we have the chance to gain valuable firsthand experience with professional media outlets in an environment far different from ours at home, but we were also exposed to a part of the world that none of us had ever seen before."

Figure 3. Transformative Citizenship Continuum

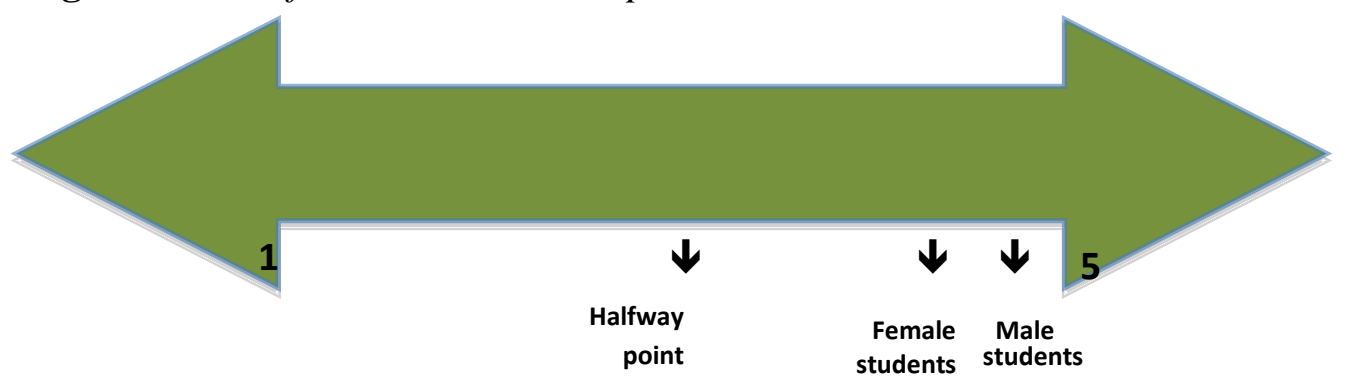

An analysis of the students' reflection papers about their experiences yielded five themes (1) Daredevil; (2) Internships; (3) Poverty; (4) Media Messages; (5) Brown Envelope Journalism. Below, these themes are elaborated on, and as earlier noted, words in the reflection papers that conveyed strong emotion and alluded to behavioral/transformative change are bolded and italicized for emphasis.

\section{Daredevil}

For the two trips the arrival in Lusaka, the capital of Zambia, was deliberately scheduled for Wednesday allowing students a day to rest before the daredevil activity. On Friday, the students were taken on an 8-hour road trip to Livingstone, the tourist capital and where the Victoria Falls resides. Locally known as Mosi-oa-Tunya (the smoke that thunders) the Victoria Falls majestically stands at 1,708 meters wide and 108 meters high, and is the world's largest single curtain of falling water. UNESCO designated it a world heritage site in 1989. It was at the Victoria Falls where the daredevil activity took place. Students were required to partake in any of the three daring activities (a) bungee jumping; (b) the gorge swing or (c) zip lining (the slide). The daredevil component was meant to psychologically aid students in overcoming anxieties, fears or apprehensions about being thrown into an alien culture. The activity was well-received, especially by male students. While they went full throttle with bungee jumping and the gorge swing, their female counterparts opted for the slide. 
[...] a male student noted thus about bungee jumping "I feel like this is the perfect "icebreaker" for the trip. If one can do this, then I feel like one can adapt quickly and get over mental obstacles that one may run into during the trip. I am glad we did it at the beginning."

[...] a female student wrote "The slide was a huge highlight of my trip. Although it was only about eight seconds long probably, it was still thrilling to be dangling over the water so high up. It sounds a little wimpy next to [...] (male student's) bungee jumping expedition, but it was worth it to me. Even though it was the simplest of the three options."

\section{Internships}

As expected, the first day was the hardest, particularly for female students. During the after-work bonding over group dinner, the students were prompted to talk about how their day was. Although expressions of frustration were commonplace especially among female students, as noted in the excerpt below, they mostly recovered within hours.

The first day of work, I was terrified. I was really disappointed that I wouldn't be working with layout and design people, so I was nervous I wouldn't do a good job. Within an hour of being there, [...] asked me if I wanted to go on assignment with her. I just followed her outside where we waited for our driver for about ten minutes. While waiting, I thought I'd ask where we were going and she told me to see the National Team. I'm pretty sure my jaw dropped because we had just been discussing how I wished I could see them and meet Herve and then that was the first place we were going.

By the second day, student acclimatization was evident. Interestingly, female students gravitated more towards sports assignments and seemed to enjoy them, as noted in the excerpt below:

The next day at the Zambia Daily Mail, I also got to cover a story that made the headline in the sports section of the paper the following day. I tagged along to the Barclays sports complex where the President made an appearance to watch the national soccer team train. Because the national team was training for the match against South Africa, which was a world cup qualifier game, the President made a point to wish them good luck. One thing I learned about the Zambian culture during this experience was if the President is at the same event you are covering, you technically are not allowed to leave until he leaves first. Because he decided to stay and watch the team train for so long, it affected my deadline for the story tremendously. The day before, I had three hours to finish my story. However, on this particular day, I only had half an hour. This forced me to 
pull myself together and learn the hard way how journalists finish their deadlines on time.

The male students, on the other hand, tended to be generalists covering anything from court news, business news, politics, sports, etc. One such male student generalist drew comparisons between his experiences at an American newspaper with the Zambian experience.

My experience at the Times of Zambia was definitely one that will help $\boldsymbol{m} \boldsymbol{e}$ in my professional career down the road. Having worked at the Roanoke Times for a few years, I was already familiar with the way a professional newspaper's newsroom works, but I think that experience helped me to further evaluate differences between an American newsroom and a Zambian one. I have concluded that the Zambian newsroom is a lot more relaxed than the one at the Roanoke Times. The looseness was also prevalent in the way that they dealt with me as an attachment. I had almost no structure to my "mini-internship" other than showing up around 8 a.m. and "knocking off" around 4:30 p.m. each day.

\section{Poverty}

Gender differences were also noted in how the students reacted to poverty, a topic that was tackled in all the female students' reflection papers. A typical reaction to poverty by female students is exemplified in the excerpt below:

When we were at the bus station in Livingstone, waiting to return to Lusaka, I was watching two children outside of my window. They were walking the street from trash can to trash can trying to pick out anything that could be useful to them. I know there's poverty in America, but it's not prevalent anywhere I have ever lived. It was very eye-opening to see those children fending for themselves.

As for male students not all of them discussed poverty. Of those who did their approach was to put the vice into a broader context:

The number one thing that was most unexpected by myself was discovering how westernized and developed Zambia actually was. I am not going to directly blame American media, but I felt that I had been exposed to only the suffering and poverty of Africa.

In terms of the most sobering of experiences, on the walk to lunch from the radio station to Manda Hill shopping mall we had to cross a bridge that went over a busy intersection, and everyday as we walked across there would be little boys emerging from under the bridge to beg for food and money. We were very hesitant to give them anything because even [...] and the other DJs would ignore them and tell us not to give them anything. 
This was tough to stomach because even in America I have never seen life that needed more attention than those little boys.

\section{Media Messages}

Another significant theme, which also helped shape how students approached internships was their reactions to media messages. Students were required to keep a media consumption log. The religiosity with which they observed this requirement is exemplified below both in the excerpt from a female student's paper, and actual practice in the case of the male student who covered a story at his internship on HIV (Figure 4).

On another day, I was even more impressed with the messages that the media was delivering. After we got back from Livingstone, one morning I turned on the news and was almost blown away with what the news anchor was discussing. The anchor was delivering a message about how the country was calling for celebrities to begin leading godly lives in order to lower the percentage of HIV and AIDS. This led me to understand that in their (sic) news, the media tries to cover health issues and other things that will ultimately benefit its (sic) people.

Figure 4. Times of Zambia story on HIV/AIDS (Published 17 May, 2012)

\begin{tabular}{|c|c|c|c|}
\hline 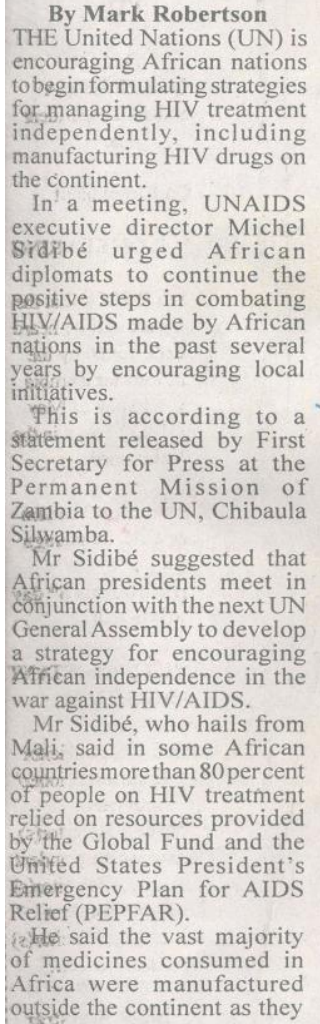 & $\begin{array}{l}\text { were primarily imported from } \\
\text { Asian nations. } \\
\text { According to Mr Sidibé, } \\
\text { a-significant percentage of } \\
\text { medicines available today } \\
\text { were also not genuine, } \\
\text { presenting anotherstruggle for } \\
\text { which African governments } \\
\text { needed to prepare. } \\
\text { "But we now need to start } \\
\text { thinking about manufacturing } \\
\text { medicines in Africa," Mr } \\
\text { Sidibé toldAfrican diplomats } \\
\text { at the African Union office in } \\
\text { New York. } \\
\text { "I have been privileged to } \\
\text { address the [New Partnership } \\
\text { for Africa's 'Development] } \\
\text { Heads of State and they asked } \\
\text { ustocomeupwith theroadmap } \\
\text { on sustainable financing } \\
\text { and mobilising additional } \\
\text { resources internally in Africa } \\
\text { for drugs and treatment," he } \\
\text { said. } \\
\text { Atleast } 1.8 \text { millionAfricans } \\
\text { die from complications } \\
\text { stemming from HIV/AIDS } \\
\text { each year and Mr Sidibé said } \\
\text { early treatment for people } \\
\text { with HIV/AIDS was crucial to } \\
\text { keeping new infections at bay. } \\
\text { Despite all this, Mr Sidibe } \\
\text { said treatment options on the } \\
\text { continent were better than } \\
\text { ever and that medicines were } \\
\text { falling in price. } \\
\text { "That doesn't mean that } \\
\text { HIV/AIDS no longer needs } \\
\text { urgent attention. We know } \\
\text { that we managed to change the } \\
\text { trajectory of this epidemic on } \\
\text { the continent but we still have }\end{array}$ & $\begin{array}{l}\text { nine million people today } \\
\text { waiting for treatment. } \\
\text { "We need to continue to } \\
\text { push to make sure that access } \\
\text { to treatment is a reality for our } \\
\text { continent," Mr Sidibé said. } \\
\text { AndGethsemane Mwizabi } \\
\text { reports that more than } 5 \text {, 000 } \\
\text { people in Kaniki and Kawama } \\
\text { townships in Ndola have } \\
\text { been trained in community- } \\
\text { led HIV/AIDS prevention } \\
\text { activities. } \\
\text { The two communities have } \\
\text { been trained through the } \\
\text { Community Mobilisation } \\
\text { for Prevention Action } \\
\text { (COM MPA C T) proje ct } \\
\text { being implemented by the } \\
\text { Population Council. } \\
\text { Population Council chief } \\
\text { of party, Chabu Kangale said } \\
\text { yesterday in an interview } \\
\text { during a COMPACT award } \\
\text { ceremony in Kaniki that } \\
\text { he was pleased as the two } \\
\text { communities achieved their } \\
\text { specific benchmarks. } \\
\text { He said the communities } \\
\text { had formed Safe Love clubs } \\
\text { that were instrumental in HIV } \\
\text { prevention inthe communities } \\
\text { by. engaging in such } \\
\text { discussions as multiple and } \\
\text { concurrent sexual partners. } \\
\text { "One of the interventions } \\
\text { we are implementing is the } \\
\text { formation of gender action } \\
\text { groups that are working to } \\
\text { educate the community on } \\
\text { the dangers of gender-based } \\
\text { violence,"Mr Kangale said. } \\
\text { And USAID/Zambia HIV/ }\end{array}$ & $\begin{array}{l}\text { Zegeye said communities } \\
\text { should be involved in finding } \\
\text { solutions for HIV to prevent } \\
\text { the further spread of the } \\
\text { epidemic in Zambia. } \\
\text { He said the residents } \\
\text { of Kaniki knew best what } \\
\text { challenges they faced in } \\
\text { fighting HIV and what } \\
\text { solutions would work in their } \\
\text { community, } \\
\text { "Today, we celebrate the } \\
\text { goals you have achieved, } \\
\text { working together as a } \\
\text { comm unity. You have } \\
\text { successfully created Safe } \\
\text { Love clubs that educate the } \\
\text { community on sex, sexuality } \\
\text { and condom use," he said. } \\
\text { Ndola District medical } \\
\text { officer, Kakungu Simpungwe } \\
\text { saidadolescentgirls shouldbe } \\
\text { protected through the creation } \\
\text { of "safe spaces". } \\
\text { She said HIV prevalence } \\
\text { was significantly higher } \\
\text { among girls compared to their } \\
\text { male counterparts. } \\
\text { DrSimpungwe said this was } \\
\text { asaresultof inter-generational } \\
\text { sex where older men were } \\
\text { having sex with girls. } \\
\text { "Young girls want to have } \\
\text { a bit of money and gifts from } \\
\text { men and end up having sexual } \\
\text { relationships that puts them at } \\
\text { risk," she said. } \\
\text { At end of the ceremony, } \\
\text { assorted sports items and } \\
\text { bicycles worth more thanK18 } \\
\text { million were awarded to the } \\
\text { community groups. }\end{array}$ \\
\hline
\end{tabular}




\section{Brown Envelope Journalism}

Brown Envelope Journalism (BEJ) is a practice that involves news sources granting monetary incentives to journalists with the expectation of adequate coverage (Kasoma, 2007). Group dinners provided an opportunity for students to talk about their experiences with BEJ, which would have otherwise been a professional culture shock had it not been covered at length during lectures. The students generally applied their own ethical standards on how they handled BEJ. While others fully participated in BEJ, others preferred not to. A male student wrote the following about his experience:

I got my first and only taste of BEJ on the first day too. Our second assignment was to go investigate and report on a recycling company. We had no idea what the purpose was of the assignment until we were told by the president/founder of the company himself. This also pointed out to me that many assignments that are taken on by the journalists are done by going in blindly. The president [...] was not interviewed as much as he told us what the story was to write. I thought to myself: "Wait, this is our job, not yours. We decide what to write." Afterwards, I took his picture and we left. After getting out of the door, my partner turned to me and showed me a wad of bills and looked absolutely perplexed. I had no idea if this was an act or not, but I was surprised too, because there were ten $\mathrm{K}$ 50,000 notes (equivalent to \$100) in her hand. The "taxi money", as it was called, was more than enough. She said to me, "I did not know what to do. He just came up to me and handed me the money and said it was for the taxi. This never happens to me." We proceeded to going back to The Daily Mail and she talked to her editor in the business department about it ... It turns out she handed out the money between herself, the editor and her colleagues. I told her I did not want it. I was hoping to set an example to keep money out of the writing.

\section{Conclusions}

This study demonstrates that journalism students highly value servicelearning and international internships as transformative pedagogies and in line with Dewey's philosophy educators should continue to explore them. In unison, the two pedagogies help the field of journalism embrace the concept of "glolocal" (global/local) citizenship. There is therefore need to start combining service learning in international internships within the same course. For example, in Journalistic Practice in Zambia, next time the author intends to incorporate a service-learning project that would encapsulate student sentiments about poverty. The project would involve identifying a non-profit organization that deals with children at the onset of the spring class. Then in the course of the semester instituting a food, clothing, or book drive while in the US. The students could use their journalistic skills to publicize the project 
using student media and other conduits. When in Zambia, a weekend could be earmarked for students to spend time at the non-profit to serve and donate the collected proceeds. The overall service-learning project would culminate in students writing and reporting about their experiences for local media outlets.

\section{References}

Britt, L. L. (2012). Why we use service-learning: A report outlining a typology of three approaches to this form of communication pedagogy. Communication Education 61(1), 80-88.

Cohen, J. \& Kinsey, D.F. (1994). "Doing Good" and scholarship: A service learning study. Journalism Educator 48(4), 4-14.

Deuze, M. (2001). Educating "New" journalists: Challenges to the curriculum. Journalism Educator 56(11).

Dewey, J. (1938). Experience and Education. Toronto: Collier-MacMillan Canada Ltd.

Freedman, E. (2010). Media, tourism, environment, and cultural issues in Australia: A case study of a study abroad program. Applied Environmental Education \& Communication 9(2), 87-95.

Freire, P. (1970). Pedagogy of the Oppressed. New York: Continuum.

Getz, J.E. (2002). Journalism Students' Perceptions of the Value of Internships. Paper presented at AEJMC, Miami Beach, FL, August 7-10. Retrieved from http://bit.ly/1Fj5v0Y

Holm, H. (2002). The Forgotten Globalization of Journalism Education. Journalism Educator 57(4), 67-71.

Israel, R. (2013). Re-birth of a Nation? Challenging "Global Citizens". Retrieved from http://bit.ly/1v2ZmnK

Kasoma, T. (2007). Brown Envelope Journalism and Professionalism in Development Reporting: A Comparison of Zambia and Ghana. Unpublished Ph.D. dissertation. University of Oregon, USA.

Morgan, W. \& Streb, M. J. (2003). First, do no harm: Student ownership and servicelearning. Metropolitan Universities: An International Forum 14(3), 36-52.

Patwardhan, P., Sarow, M. \& Stuart, B. (2013). Infusing Global Learning in the Journalism/Mass Communication Curriculum: A case Study. Paper presented at the World Journalism Education Congress, Mechelen, Belgium, 3-5 July.

Pine, N. (2008). Service learning in a basic writing class: A best case scenario. Journal of Basic Writing 27(2), 29-55.

Sapp, D. A. \& Crabtree, R. D. (2002). A laboratory in citizenship: service learning in the technical communication classroom. Technical Communication Quarterly 11, 411-431.

Silverman, D. A. (2008). Service Learning Projects in the PR Writing Course. Paper presented at the National Communication Association Convention. San Diego, California.

Steeves, H. L. (2006). Experiencing international communication: An internship program in Ghana, West Africa. Journalism \& Mass Communication Educator 60,4 .

The National Service-Learning Clearinghouse. (2011). What is Service-Learning. Retrieved from http://bit.ly/1L0h9iB. 
